\title{
Was Sleep a Problem for the Elderly During COVID-19?
}

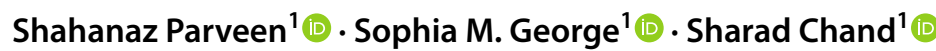

Received: 8 June 2021 / Revised: 26 July 2021 / Accepted: 12 August 2021 / Published online: 6 September 2021

(c) The Author(s), under exclusive licence to Springer Nature Singapore Pte Ltd. 2021

\begin{abstract}
Over the past few decades, the population of geriatrics has seen an exponential rise and it is well known that the prevalence of chronic diseases and other associated comorbidities is higher among them which in turn, has an established association with sleep disorders. During these unprecedented circumstances, geriatrics are predisposed to be at an increased risk of sleep disorders due to the social isolation and loneliness imposed on them by the lockdowns. The fact that older adults are at a greater risk of contracting the virus due to the presence of comorbidities and the high virulence adds on to the existing risk of sleep disturbances. A lack of sleep in these circumstances has the potential to add on to the vicious cycle of sleep disorders predisposed by chronic disease and vice versa. Mental health, sleep and the presence of comorbidities are closely interlinked and they often tend to overlap. Research in sleep has established insomnia to be the most commonly diagnosed sleep disorder affecting almost $50 \%$ of the older adults which can subsequently, elevate their risk of falls. This prevalence of sleep disorders is hypothesized to increase during the second wave of the COVID-19 pandemic and a good sleep routine needs to be advocated for to improve the quality of life of this population. However, scientific evidence concerning this is scarce and this review aims to highlight the significance of sleep and urges its readers to undertake studies that investigate the architecture of sleep amongst older adults during the pandemic.
\end{abstract}

Keywords Insomnia $\cdot$ Lockdown $\cdot$ Pandemic $\cdot$ Isolation $\cdot$ Quality of life

\section{Introduction}

The epidemiology of older adults is set to grow exponentially in the coming years with the availability of better insurance coverage and health care facilities. In the United States, $15 \%$ of the total population was composed of older adults in the year 2016. However, it has been projected that $21 \%$ of the substratum is likely to account for older adults by 2040 [1].

COVID-19 is a single stranded virus that has now been recognized to be a pandemic by the World Health Organization (WHO). The virus transfers itself from an infected individual to another through droplets released while coughing, sneezing or contact with surfaces and material. Over the past 1 year of the pandemic, the virus has managed to

Sophia M. George

Email-sophiamgeorge.108@gmail.com

1 Department of Pharmacy Practice, NGSM Institute of Pharmaceutical Sciences, NITTE (Deemed to be University), Paneer, Deralakatte, Mangalore, Karnataka 575018, India mutate itself into several variants that have raised its rate of infectivity and mortality simultaneously in the general public [2]. Scientists have not been able to derive a definite cure for the coronavirus disease apart from the adoption of primary preventive measures, such as the strict wearing of masks, frequent sanitization of hands and the maintenance of social distancing [3]. As part of secondary prevention, several existing drugs, such as hydroxychloroquine, ivermectin, and remdesivir, have been repurposed to mitigate the clinical effects of COVID-19 [4]. Vaccines that have been developed by pharmaceutical companies, such as Pfizer, Bharat Biotech, Oxford-AstraZeneca, have by far proven to be the most effective strategy to curb the spread of the disease [5].

The tropical nation of India with a massive population of 1.3 billion people documented the first case of the single stranded virus on January 27, 2020. With the already existent dense population of the country and the high probability for a rapid spread of the contagious virus, the government of India imposed a nation-wide lockdown on March 25th, 2020 for a period of 3 weeks. The lockdown planned to completely restrict large gatherings and mobility of any kind. During this period, older adults came face to face with 
challenges in meeting their daily needs such as the inability to find domestic help or support to perform many of their routine tasks. It soon became widespread that geriatrics were at the highest risk of contracting the infection and that they also had the highest mortality as a consequence of their advanced age. In addition, it is well known in the scientific community that a large proportion of these older adults have a long list of comorbidities as a result of ageing. The repeated warnings that were publicized through media and by their own kin regarding the potential for high risk of complications if they tested positive for COVID-19 only further worsened their sense of helplessness, loneliness and anxiety. Those who lived in the setup of a joint family were able to avail more support than those whose kids were living in countries abroad $[1,6]$.

With all the current and well-known problems faced by this group, we would like to hypothesize that the sleep hygiene in older adults would have been drastically affected. However, it has not yet been assessed or investigated by the scientific community.

\section{Impact of COVID-19 on Older Adults}

With the increasing spread of the virus during the early 2020 in the United States, a disproportionate distribution of disease incidence was noted. Older patients experienced a far greater number of adverse effects in addition to all the severe complications and heightened mortality. There were also a lot of concerns with disruptions in their daily routine and limited access to health care. This vulnerable group had the hardest time adapting to the newly found isolation that began to exacerbate mental health conditions [7]. It was stated by the WHO that more than 95\% of COVID-19 deaths were amongst those who were greater than 60 years. The Centres of Disease Control and Prevention in China submitted confirming results that showed a gradual increase in the fatality rate with advancing age. The reported percentile of fatality was $3.6 \%$ for adults in their $60 \mathrm{~s}, 8 \%$ for those in their $70 \mathrm{~s}$ and $14.8 \%$ for people who were beyond 80 years [8].

The geriatric population is found to have a lower reactivity to stress on a general basis along with a comparatively better emotional regulation and physical well-being in comparison to their younger counterparts. However, the magnitude and duration of the COVID-19 crisis has posed concerns of a mental health crisis to the otherwise stable mental health of older adults [9]. Loneliness has been described as a complicated and highly subjective emotion that often mutually coexists with a lack of connectivity or communion with others. There is a lacunae between the actual and the expected quality and frequency of social interaction during an experience of loneliness almost always [10]. The already existent problem of social isolation amongst geriatrics has only been aggravated due to the pandemic. Social contacts and interactions dwindle with advancing age due to chronic comorbidities, death of life partners and friends which only further, lowers the engagement of older adults with society [11]. The resulting social isolation and the need to isolate oneself when tested positive or as a preventive measure only furthers the odds of anxiety, depression, cognitive decline, cardiovascular disease and mortality rate amongst them [12-15].

\section{The Interlink Between Comorbidities and Sleep in the Elderly}

Geriatrics has an entire medical speciality of its own because of the complex changes in their pharmacokinetic and pharmacodynamic profile. They are more prone to become breeding grounds for long term diseases, such as diabetes, respiratory illnesses, and cardiovascular impairment. Credible scientific literature published during the COVID-19 has clearly stated that the risk of facing a severe form of COVID19 and death were strongly tied to advanced age, comorbidities and a compromised immune system which only heightens their odds of contracting the virus [8]. Chronic health conditions are common in elderly persons, and comorbidity is expected in more than half of the people of the age above 65 years. In a study conducted on 4126 elder participants, it was reported that $29 \%$ of the subjects had two or more health conditions. It was also stated that the most prevailing health conditions were hypertension (57\%), followed by diabetes (20\%), CAD (15\%), cancer (9\%) and CVD (9\%) [16-18].

\subsection{Diabetes}

The prevalence of diabetes increases with increasing age as with an advancement in age, insulin resistance increases and pancreatic islet functioning is impaired resulting in type 2 diabetes. According to a recent survey conducted in the US, the prevalence of diabetes among the elderly varied from 22 to $33 \%$ [19]. Furthermore, the progression of diabetes can also lead to cognitive impairment and dementia. A cross sectional study conducted in US screened 66,813 elderly patients to find that $10.4 \%$ of the older adults with cognitive impairment were diabetic [20]. Several studies have established that sleep could play a key role in determining the risk of developing diabetes. Spiegel and his colleagues conducted a study and reported that the deprivation of sleep altered insulin signaling within adipocytes which could lead to insulin resistance. Also, it was concluded that sleep restriction increased grehlin and decreased leptin hormones resulting in a subsequent increase in physiologic hunger and an elevation of blood glucose level [21]. 


\subsection{Cardiovascular Disease}

The risk of cardiovascular disease (CVD) is heightened with age as well. The prevalence of hypertension, CHD, heart failure and stroke were reported as $70-75 \%$ in adults aged $60-79$ years and $79-86 \%$ in adults aged above 80 years according to the heart disease and Stroke Statistics of 2009 [22]. Out of these, coronary heart disease was reported as the main cause of CVD-related death in 2005. It is evident that with advancing age, risk factors, such as obesity, diabetes, and hypertension, only add on to the chances of developing CVD. In addition to it, diastolic-systolic dysfunction and electrical dysfunction may cause heart failure, atrial fibrillation and other CVDs in older adults. The developments of these diseases are also linked to various factors, such as oxidative stress, inflammation, and apoptosis [23]. Reduced sleep is a crucial risk factor and decreased sleep can activate the sympathetic nervous system and consequentially, elevate one's blood pressure leading to adverse cardiovascular consequences [24].

\subsection{Pulmonary Disorders}

Chronic obstructive pulmonary disease (COPD) is a commonly diagnosed disease and is a disease of high burden among the elderly. A cross sectional study was conducted amongst older adults (above 65 years) with COPD in Japan using a regional COPD registry database. This population was found to have a high prevalence of dyspnoea, poorer activities of daily living (ADL), a lower exercise tolerance and a much higher incidence (all $p<0.05$ ) of COPD exacerbations in comparison to their younger counterparts [25]. This chronic pulmonary condition accounts for the highest cause of morbidity and mortality and COPD tends to often get more complex when present alongside sleep disorders [26]. The occurrence of sleep disorders such as insomnia is greatly increased among these patients [27]. This can be confirmed by a study which reported that insomnia diagnosed as per DSM-IV criteria was reported among $32.9 \%$ of those with a history of COPD in comparison to only $20.3 \%$ without the chronic condition [28]. Patients with COPD and insomnia reported a very poor self-reported sleep quality in contrast to those without and the former were predicted to suffer from more drowsiness during the daytime [29]. Clinically significant nocturnal hypoxemia and a daytime saturation between 90 and $95 \%$ was reported in almost $70 \%$ of the patients with COPD $[30,31]$. As the frequency of these nocturnal desaturations increase, the occurrence of cardiac arrhythmias is also likely to simultaneously observe an upward trend [32]. Also, a higher mortality has been documented among COPD patients with nocturnal hypoxemia than those without the medical condition [33]. Hence, one can conclude that the burden of COPD is relatively higher in the elderly and the diagnosis of COPD often leads to a corresponding increase in sleep disorders, such as insomnia and nocturnal hypoxemia [29, 31, 33].

\subsection{Mental Health in Older Adults}

\subsubsection{Stress}

It is common for older people to experience stressors that are more likely to occur later in life like the constant loss of capacities and decline in one's functional ability. This vulnerable group is highly likely to experience events such as bereavement or a change in the status of their financial independence on retirement. These factors coupled with their physiological decline results in social isolation, loneliness and instability in their mental health [34-39]. Mental health has a direct impact on one's physical health and vice versa. Geriatric patients who are known cases of cardiovascular diseases are at a higher risk of stress and depression and if untreated within real time could adversely affect the individual's health outcomes [40]. Elder abuse is a term that is well known amongst this age group as well. Older individuals are subject to abuse on a day-to-day basis. Abuse among them includes psychological, physical, verbal, financial and sexual abuse. Abandonment, neglect and a fundamental loss of dignity and respect is also not new for them and it could have potential long standing psychological repercussions [41].

\subsubsection{Anxiety}

Anxiety has become a common occurrence amongst geriatrics and it affects almost 10-20\% of this population. However, it often goes unnoticed and untreated in most cases. This could have serious consequences, such as the worsening in their cognitive function, increasing disability and a decline in physical health. Some of the stressors that come along with an advanced age encompass a poor health status and memory issues that are capable of triggering an anxious state of mind. Usual fears about ageing itself could lead to anxiety. It has been noticed that a large group of older adults are possessed by the fear of falling and the fear of being financially dependent and a burden on their family members. They are often victimised and left alone for long periods of time [36, 42]. Anxiety and its related disorders have a strong link with disturbances in sleep. Emotions of worry and fear lead to a mind that is racing, also termed as a hyperarousal. Hyperarousal in turn, is a weighty contributor to insomnia [43]. Anxiety worsens sleep efficiency and increases the number of awakenings at night [44]. It increases drowsiness during the day due to the affected quality of sleep $[45,46]$. 


\subsubsection{Depression}

As per statistical reports, unipolar depression occurs in 7\% of all the general older adults. Depression is often overlooked and not treated adequately, since they get hidden amongst the other comorbidities faced by them. Geriatrics with symptoms of depression have noted to have a decline in their functional status in comparison to those with chronic lung diseases, hypertension and diabetes. This mental health condition eventually also affects the utilisation of health care services and other health care related expenses [41]. Approximately, $75 \%$ of those who are depressed tend to display symptoms of insomnia. Sleep disturbances such as hypersomnia have been diagnosed in $10 \%$ of the elderly population [47].

\subsection{Neurological Disorders}

It includes epilepsy, dementia, Alzheimer's disease, Parkinson's disease, brain tumor and the prevalence of these diseases increases with age. According to a study conducted in Africa with 187 older subjects, it was reported that $14 \%$ had lumbar arthrosis, $12.4 \%$ had dementia, $10.2 \%$ had Parkinson's disease and $9.1 \%$ had polyneuropathy [46-48]. The functioning of neurons, glial cells, vascular cells and the basal lamina matrix decreases with age which positions them to be at a high risk of developing neurological disorders [48]. Deprivation of sleep is also said to give rise to various CNS disorders. The development of Alzheimer's disease may be associated with elevated tau levels in the brain that is closely associated with reduced sleep. In a study reported by Spira et al., on 214 Swedish adults aged above 75 years, the results clearly showed that a prolonged decrease in sleep in the elderly was interlinked with $70-100 \%$ greater odds of developing dementia and Alzheimer's disease [49]. Decreased sleep is also capable of impairing the brain's electrical and hormonal activity which may lead to a diagnosis of epilepsy in the older population.

\subsection{Cancer}

Age is a known risk factor for cancer. The most frequently occurring cancer types among the elderly are lung, prostate, breast and colorectal cancer. According to a study done in the United States (US), approximately $60 \%$ of the cancer cases were found in adults above 65 years of age with breast cancer being the most common. A study conducted in Turkey reported that $40.7 \%$ of the elderly women had breast cancer [50]. Risk factors such as prolonged environmental or occupational exposures to chemical and physical agents, tobacco smoke and viral infections could lead to various types of cancer in this vulnerable group. Such persistent environmental exposures can cause molecular and cellular changes in the mammary tissue during puberty leading to the development of breast cancer many years later [51]. An extended lack of sleep can also progressively cause cancer especially in elderly women and scientific research has convincing evidence to show that working overnight shifts for several years could lead to reduced levels of melatonin, and eventually lead to breast cancer [52]. The details on the interlink between sleep, chronic diseases and COVID-19 is referenced in Table 1.

\section{Recommendations}

It has already been established that the prevalence of chronic diseases and a weakened immune system in comparison to young adults is higher among geriatrics. In addition, the psychological burden due to the loneliness, isolation and imposed physical restrictions has also adversely affected them. As evidenced in scientific literature, the incidence and severity of the COVID-19 pandemic was higher among those with chronic diseases. On the basis of the established relation between disturbed sleep patterns, chronic diseases and the high incidence and virulence of the virus in those with comorbidities, we have tried to establish the hypothesis of increased sleep disturbances among the elderly during the pandemic with respect to the above linear relationship. However, there exists a paucity of data available on the exact correlation between these three variables (sleep, elderly, and COVID-19). We authors would like to recommend the need for researchers to conduct scientific studies and gain insight on the exact relationship among these variables and quantify the actual impact of the pandemic on sleep among older adults. Confounding factors such as family health, communication, levels of recreational activity, diet patterns, lifestyle and compliance with the COVID-19 protocols also need to be investigated for its influence on achieving a good sleep which remains a limitation of this review.

\section{Conclusion}

The prevalence of mental health disturbances and other chronic inflammatory states amongst the geriatric population is already at its peak. The pandemic has relatively affected the population with co-existing comorbidities to a greater extent in comparison to the others. The feelings of helplessness and loneliness are additional and potential factors that would have caused a further decline in their mental and physical status. Thus, we hypothesize that the pandemic would only have worsened the existing sleep statistics in this population. However, these disturbed patterns of sleep have not been studied and hence, the purpose of this review is to reiterate this close inter-link between the 


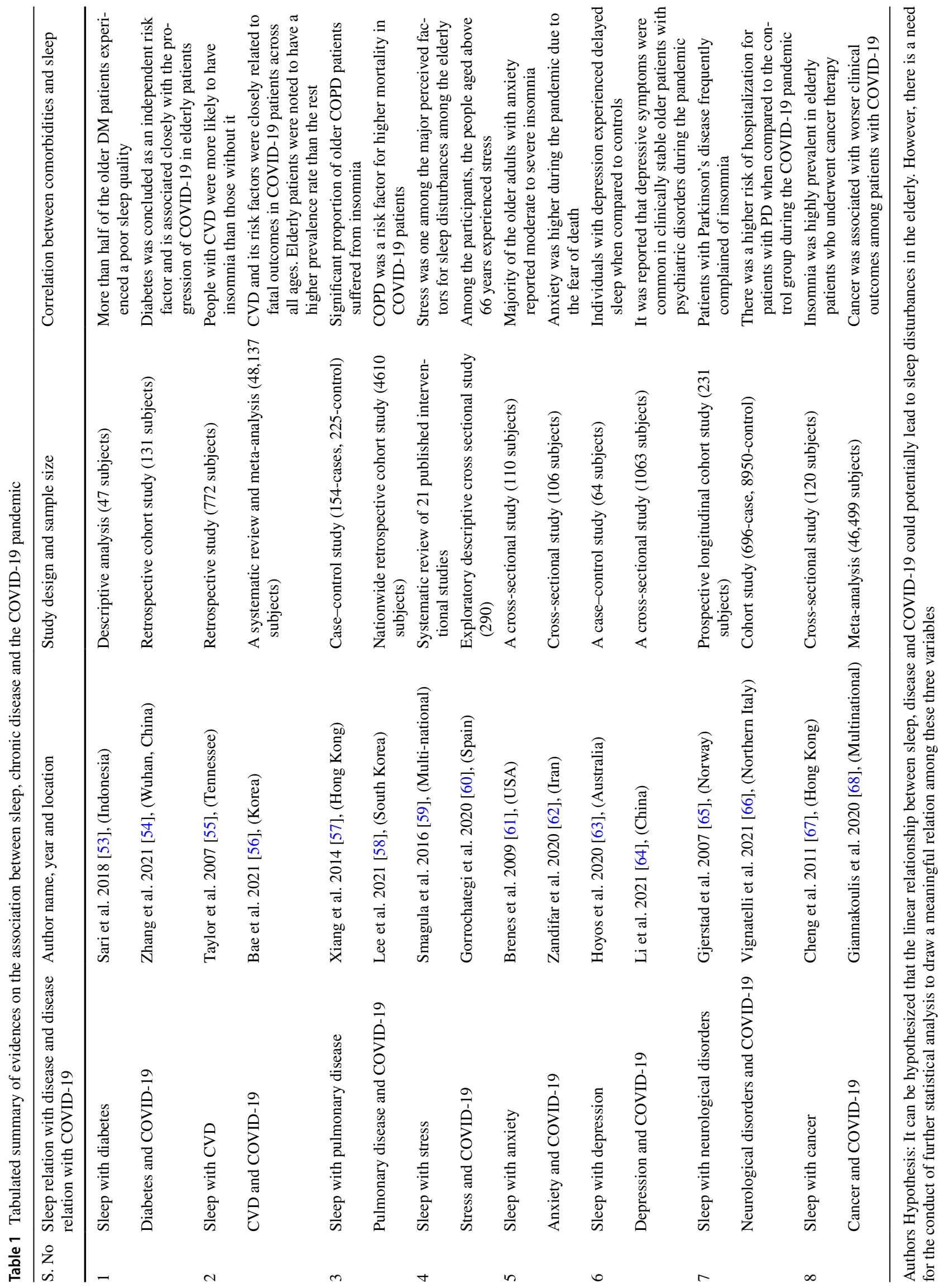


physiological profile of older adults and sleep. It also calls for more methodically designed studies to be conducted to assess the impact of the pandemic on the sleep hygiene of older adults.

Acknowledgements We authors would like to thank NGSM Institute of Pharmaceutical Sciences for their relentless support throughout the review.

Author Contributions All the authors contribute equally in the review article.

\section{Declarations}

Conflict of interest The authors declare no conflict of interest.

Ethical Approval Not applicable.

Consent Statement Not required.

\section{References}

1. 2017 Profile of older Americans. Administration for community living. 2018. https://acl.gov/sites/default/files/Aging\%20and\% 20Disability\%20in\%20America/2017OlderAmericansProfile. pdf). Accessed 7 March 2021.

2. Samudrala PK, Kumar P, Choudhary K, Thakur N, Wadekar GS, Dayaramani R, et al. Virology, pathogenesis, diagnosis and in-line treatment of COVID-19. Eur J Pharmacol. 2020;15(883): 173375. https://doi.org/10.1016/j.ejphar.2020.173375.

3. Habas K, Nganwuchu C, Shahzad F, Gopalan R, Haque M, Rahman S, et al. Resolution of coronavirus disease 2019 (COVID-19). Expert Rev Anti Infect Ther. 2020;18(12):1201-11.

4. Stasi C, Fallani S, Voller F, Silvestri C. Treatment for COVID-19: an overview. Eur J Pharmacol. 2020;889:173644.

5. Hodgson SH, Mansatta K, Mallett G, Harris V, Emary KRW, Pollard AJ. What defines an efficacious COVID-19 vaccine? A review of the challenges assessing the clinical efficacy of vaccines against SARS-CoV-2. Lancet Infect Dis. 2021;21(2):e26-35. https://doi. org/10.1016/S1473-3099(20)30773-8.

6. Biswas S. India coronavirus: why lock down $1.3 \mathrm{bn}$ people? BBC News, March 24. 2020. Accessed 7 March 2021.

7. Vahia IV, Jeste DV, Reynolds CF. Older adults and the mental health effects of COVID-19. JAMA. 2020;324(22):2253-4.

8. The impact of the COVID-19 pandemic on older adults. Medical News Today. https://www.medicalnewstoday.com/articles/ the-impact-of-the-covid-19-pandemic-on-older-adults\#Old-ageand-preexisting-health-conditions0. Accessed 9 March 2021.

9. Lee EE, Depp C, Palmer BW, Glorioso D, Daly R, Liu J, et al. High prevalence and adverse health effects of loneliness in community-dwelling adults across the lifespan. Int Psychogeriatr. 2019;31(10):1447-62.

10. Victor CR, Scambler SJ, Bowling A, Bond J. The prevalence of, and risk factors for, loneliness in later life: a survey of older people in Great Britain. Ageing Soc. 2005;25(6):357-75.

11. Victor CR, Bowling A. A longitudinal analysis of loneliness among older people in Great Britain. J Psychol. 2012;146(3):313-31.

12. Barth J, Schneider S, Von Känel R. Lack of social support in the etiology and the prognosis of coronary heart disease: a systematic review and meta-analysis. Psychosom Med. 2010;72(3):229-38.
13. Holt-Lunstad J, Smith TB, Layton JB. Social relationships and mortality risk: a meta-analytic review. PLoS Med. 2010;7(7):e1000316.

14. Santini Z, Jose P, Cornwell E, Koyanagi A, Nielsen L, Hinrichsen $\mathrm{C}$, et al. Social disconnectedness, perceived isolation, and symptoms of depression and anxiety among older Americans (NSHAP): a longitudinal mediation analysis. Lancet Public Health. 2020;5:e62-70.

15. Shankar A, McMunn A, Demakakos P, Hamer M, Steptoe A. Social isolation and loneliness: prospective associations with functional status in older adults. Health Psychol. 2017;36(2):179-87.

16. Fillenbaum GG, Pieper CF, Cohen HJ, Cornoni-Huntley JC, Guralnik JM. Comorbidity of five chronic health conditions in elderly community residents: determinants and impact on mortality. J Gerontol A Biol Sci Med Sci. 2000;55(2):M84-9.

17. Wang LM, Chen ZH, Zhang M, Zhao ZP, Huang ZJ, Zhang X, et al. Study of the prevalence and disease burden of chronic disease in the elderly in China. Zhonghua Liu Xing Bing Xue Za Zhi. 2019;40(3):277-83.

18. Gao Y, Ping Z, Pei X, Cai Y, Wang J. Multi-correspondence analysis of the status and related factors of chronic diseases multimorbidity in middle-aged and elderly people in China in 2009. Wei Sheng Yan Jiu. 2020;49(5):844-9.

19. Kirkman MS, Briscoe VJ, Clark N, Florez H, Haas LB, Halter JB, et al. Diabetes in older adults. Diabetes Care. 2012;35(12):2650-64.

20. Corriere M, Rooparinesingh N, Kalyani RR. Epidemiology of diabetes and diabetes complications in the elderly: an emerging public health burden. Curr Diabetes Rep. 2013;13(6):805-13.

21. Grandner MA, Seixas A, Shetty S, Shenoy S. Sleep duration and diabetes risk: population trends and potential mechanisms. Curr Diabetes Rep. 2016;16(11):1-4.

22. Madhavan MV, Gersh BJ, Alexander KP, Granger CB, Stone GW. Coronary artery disease in patients $\geq 80$ years of age. J Am Coll Cardiol. 2018;71(18):2015-40.

23. Yazdanyar A, Newman AB. The burden of cardiovascular disease in the elderly: morbidity, mortality, and costs. Clin Geriatr Med. 2009;25(4):563-77.

24. Thomas SJ, Calhoun D. Sleep, insomnia, and hypertension: current findings and future directions. J Am Soc Hypertens. 2017;11(2):122-9.

25. Kobayashi S, Yanai M, Hanagama M, Yamanda S. Burden of chronic obstructive pulmonary disease in the elderly population. Respir Investig. 2014;52(5):296-301.

26. Budhiraja R, Siddiqi TA, Quan SF. Sleep disorders in chronic obstructive pulmonary disease: etiology, impact, and management. J Clin Sleep Med. 2015;11(3):259-70.

27. Valipour A, Lavie P, Lothaller H, Mikulic I, Burghuber OC. Sleep profile and symptoms of sleep disorders in patients with stable mild to moderate chronic obstructive pulmonary disease. Sleep Med. 2011;12(4):367-72.

28. Budhiraja R, Roth T, Hudgel DW, Budhiraja P, Drake CL. Prevalence and polysomnographic correlates of insomnia comorbid with medical disorders. Sleep. 2011;34(7):859-67.

29. Budhiraja R, Parthasarathy S, Budhiraja P, Habib MP, Wendel C, Quan SF. Insomnia in patients with COPD. Sleep. 2012;35(3):369-75.

30. Lewis CA, Fergusson W, Eaton T, Zeng I, Kolbe J. Isolated nocturnal desaturation in COPD: prevalence and impact on quality of life and sleep. Thorax. 2009;64(2):133-8.

31. Chaouat A, Weitzenblum E, Kessler R, Charpentier C, Ehrhart $\mathrm{M}$, Levi-Valensi $\mathrm{P}$, et al. Sleep-related $\mathrm{O} 2$ desaturation and daytime pulmonary haemodynamics in COPD patients with mild hypoxaemia. Eur Respir J. 1997;10(8):1730-5. 
32. Perin C, Fagondes SC, Casarotto FC, Pinotti AF, Menna Barreto SS, Dalcin PT. Sleep findings and predictors of sleep desaturation in adult cystic fibrosis patients. Sleep Breath. 2012;16(4):1041-8.

33. Fletcher EC, Donner CF, Midgren B, Zielinski J, Levi-Valensi $\mathrm{P}$, Braghiroli A, et al. Survival in COPD patients with a daytime $\mathrm{PaO} 2$ greater than $60 \mathrm{~mm} \mathrm{Hg}$ with and without nocturnal oxyhemoglobin desaturation. Chest. 1992;101(3):649-55.

34. Whitehead BR. COVID-19 as a stressor: pandemic expectations, perceived stress, and negative affect in older adults. J Gerontol B Psychol Sci Soc Sci. 2021;76(2):e59-64.

35. Whitehead BR, Torossian E. Older adults' experience of the COVID-19 pandemic: a mixed-methods analysis of stresses and joys. Gerontologist. 2021;61(1):36-47.

36. Knight L, Hester M. Domestic violence and mental health in older adults. Int Rev Psychiatry. 2016;28(5):464-74.

37. Baker E, Clark LL. Biopsychopharmacosocial approach to assess impact of social distancing and isolation on mental health in older adults. Br J Community Nurs. 2020;25(5):231-8.

38. Gustavsson J, Beckman L. Compliance to recommendations and mental health consequences among elderly in sweden during the initial phase of the COVID-19 pandemic-a cross sectional online survey. Int J Environ Res Public Health. 2020;17(15):5380.

39. Freedman A, Nicolle J. Social isolation and loneliness: the new geriatric giants: approach for primary care. Can Fam Physician. 2020;66(3):176-82.

40. Şen F, Meriç M. Determination of abuse and depression in the elderly. J Elder Abuse Negl. 2020;32(1):60-71.

41. Mental health of older adults. World Health Organisation. https:// www.who.int/news-room/fact-sheets/detail/mental-health-ofolder-adults. Accessed 7 March 2021.

42. Anxiety and older adults: overcoming worry and fear. Geriatric Mental Health Foundation. https://www.aagponline.org/index. $\mathrm{php} ? \mathrm{src}=$ gendocs $\& \mathrm{ref}=$ anxiety\#: $:$ text $=$ Anxiety $\% 20 \mathrm{is} \% 20 \mathrm{a} \%$ 20common $\% 20$ illness, most\%20typical\%20type\%20of\%20anx iety. Accessed 7 March 2020.

43. Kalmbach DA, Cuamatzi-Castelan AS, Tonnu CV, Tran KM, Anderson JR, Roth T, et al. Hyperarousal and sleep reactivity in insomnia: current insights. Nat Sci Sleep. 2018;10:193-201.

44. Spira AP, Stone K, Beaudreau SA, Ancoli-Israel S, Yaffe K. Anxiety symptoms and objectively measured sleep quality in older women. Am J Geriatr Psychiatry. 2009;2:136-43.

45. Koffel E, Watson D. The two-factor structure of sleep complaints and its relation to depression and anxiety. J Abnorm Psychol. 2009;118(1):183-94.

46. Van den Berg JF, Luijendijk HJ, Tulen JH, Hofman A, Neven AK, Tiemeier H. Sleep in depression and anxiety disorders: a population-based study of elderly persons. J Clin Psychiatry. 2009;70(8):1105-13.

47. Nutt D, Wilson S, Paterson L. Sleep disorders as core symptoms of depression. Dialogues Clin Neurosci. 2008;10(3):329-36.

48. Kowalska M, Owecki M, Prendecki M, Wize K, Nowakowska J, Kozubski W, et al. Aging and neurological diseases. Senescence Physiol Pathol. 2017. https://doi.org/10.5772/intechopen.69499.

49. Spira AP, Chen-Edinboro LP, Wu MN, Yaffe K. Impact of sleep on the risk of cognitive decline and dementia. Curr Opin Psychiatry. 2014;27(6):478.

50. Cinar D, Tas D. Cancer in the elderly. North Clin Istanb. 2015;2(1):73-80.

51. White MC, Holman DM, Boehm JE, Peipins LA, Grossman M, Henley SJ. Age and cancer risk: a potentially modifiable relationship. Am J Prev Med. 2014;46(3):S7-15.

52. Fakih R, Rahal M, Hilal L, Hamieh L, Dany M, Karam S, et al. Prevalence and severity of sleep disturbances among patients with early breast cancer. Indian J Palliat Care. 2018;24(1):35-8.

53. Sari CW, Parida U, Adiningsih D. Sleep quality of elderly with diabetes melitus. J Nurs Care. 2018;1(2):140-8.
54. Zhang P, Wang M, Wang Y, Wang Y, Li T, Zeng J, et al. Risk factors associated with the progression of COVID-19 in elderly diabetes patients. Diabetes Res Clin Pract. 2021;171:108550.

55. Taylor DJ, Mallory LJ, Lichstein KL, Durrence HH, Riedel BW, Bush AJ. Comorbidity of chronic insomnia with medical problems. Sleep. 2007;30(2):213-8.

56. Bae S, Kim SR, Kim MN, Shim WJ, Park SM. Impact of cardiovascular disease and risk factors on fatal outcomes in patients with COVID-19 according to age: a systematic review and metaanalysis. Heart. 2021;107(5):373-80.

57. Xiang YT, Wong TS, Tsoh J, Ungvari GS, Correll CU, Ko FW, et al. Insomnia in older adults with chronic obstructive pulmonary disease (COPD) in Hong Kong: a case-control study. COPD J Chronic Obstr Pulm Dis. 2014;11(3):319-24.

58. Lee SC, Son KJ, Han CH, Park SC, Jung JY. Impact of COPD on COVID-19 prognosis: a nationwide population-based study in South Korea. Sci Rep. 2021;11(1):1-8.

59. Hoyos CM, Gordon C, Terpening Z, Norrie L, Lewis SJ, Hickie IB, et al. Circadian rhythm and sleep alterations in older people with lifetime depression: a case-control study. BMC Psychiatry. 2020;20:1-9.

60. Li W, Zhao N, Yan X, Zou S, Wang H, Li Y, et al. The prevalence of depressive and anxiety symptoms and their associations with quality of life among clinically stable older patients with psychiatric disorders during the COVID-19 pandemic. Transl Psychiatry. 2021;11(1):1-8.

61. Brenes GA, Miller ME, Stanley MA, Williamson JD, Knudson $\mathrm{M}, \mathrm{McC}$ all WV. Insomnia in older adults with generalized anxiety disorder. Am J Geriatr Psychiatry. 2009;17(6):465-72.

62. Zandifar A, Badrfam R, Yazdani S, Arzaghi SM, Rahimi F, Ghasemi S, et al. Prevalence and severity of depression, anxiety, stress and perceived stress in hospitalized patients with COVID-19. J Diabetes Metab Disord. 2020;19(2):1431-8.

63. Smagula SF, Stone KL, Fabio A, Cauley JA. Risk factors for sleep disturbances in older adults: Evidence from prospective studies. Sleep Med Rev. 2016;25:21-30.

64. Picaza GM, Eiguren MA, Dosil SM, Ozamiz EN. Stress, anxiety, and depression in people aged over 60 in the COVID-19 outbreak in a sample collected in Northern Spain. Am J Geriatr Psychiatry. 2020;28(9):993-8.

65. Gjerstad MD, Wentzel-Larsen T, Aarsland D, Larsen JP. Insomnia in Parkinson's disease: frequency and progression over time. J Neurol Neurosurg Psychiatry. 2007;78(5):476-9.

66. Vignatelli L, Zenesini C, Belotti LM, Baldin E, Bonavina G, Calandra-Buonaura G, et al. Risk of hospitalization and death for COVID-19 in people with Parkinson's disease or parkinsonism. Mov Disord. 2021;36(1):1-10.

67. Cheng KK, Lee DT. Effects of pain, fatigue, insomnia, and mood disturbance on functional status and quality of life of elderly patients with cancer. Crit Rev Oncol Hematol. 2011;78(2):127-37.

68. Giannakoulis VG, Papoutsi E, Siempos II. Effect of cancer on clinical outcomes of patients with COVID-19: a meta-analysis of patient data. JCO Glob Oncol. 2020;6:799-808.

69. Andrews MA, Areekal B, Rajesh KR, Krishnan J, Suryakala R, Krishnan B, Muraly CP, Santhosh PV. First confirmed case of COVID-19 infection in India: a case report. Indian J Med Res. 2020;151(5):490-2. https://doi.org/10.4103/ijmr.IJMR_2131_20.

Publisher's Note Springer Nature remains neutral with regard to jurisdictional claims in published maps and institutional affiliations. 